\title{
A retrospective study of Creutzfeldt-Jakob disease in England and Wales 1970-79 I: Clinical features
}

\author{
RG WILL, ${ }^{*}$ WB MATTHEWS \\ From the University Department of Clinical Neurology, The Radcliffe Infirmary, Oxford, UK
}

SUMMARY A comprehensive search yielded 121 confirmed cases of Creutzfeldt-Jakob disease who died in England and Wales in the decade 1970-79, and 31 probable cases. The clinical features and the results of investigation are described. Three subgroups of patients were distinguished by clinical characteristics and contrasting course.

Creutzfeldt-Jakob disease is transmissible in the laboratory to sub-human primates ${ }^{1}$ and other animals ${ }^{2}$ and may be accidentally transmitted to man. ${ }^{3}$ Whether it is naturally transmissible and if so by what means, has not been determined. As part of an epidemiological study of these aspects a retrospective survey of the disease in England and Wales for the decade 1970-79 was undertaken. The present communication is concerned with the clinical features, the recognition of cases being of obvious relevance to the epidemiology.

\section{Methods}

Cases were ascertained from three sources. A list of pathologically confirmed cases was available from an earlier study. ${ }^{4}$ All neurologists and neuropathologists were asked to notify cases. Death certificates in which Creutzfeldt-Jakob disease or an equivalent was mentioned were obtained. In the 8th ICD revision Creutzfeldt-Jakob disease does not have a separate rubric. Certificates were therefore obtained for patients known to have died of Creutzfeldt-Jakob disease. The majority had been coded under two rubrics (333.9 and 781.7). All certificates under these rubrics for the years 1970-78 were obtained. In 1979 the 9th ICD revision came into effect, with a separate rubric for Creutzfeldt-Jakob disease, and these certificates were also obtained.

Cases from whatever source were classified by previously published criteria ${ }^{5}$ as definite, probable or possible cases. Briefly, a definite diagnosis demands rapid dementia, typical EEG changes, certain commonly encountered clinical signs and histological confirmation of neuronal loss, *Present address: The National Hospital for Nervous Diseases,
Queen Square, London WC1N 3BG.

Address for reprint requests: Professor WB Matthews, Radcliffe Infirmary, Oxford OX2 6HE, UK.

Received 30 August 1983. Accepted 24 September 1983 astrocytosis and spongiform degeneration of appropriate distribution. Probable cases are similar but without histology. In possible cases the typical EEG is not required. These criteria can usually be successfully applied but certain exceptions will be mentioned below.

Hospital notes were sought for all cases notified as dying of Creutzfeldt-Jakob disease and in the great majority were highly informative. However, in 20 of 175 notified cases no details could be obtained, although from enquiry at local hospitals it is unlikely that Creutzfeldt-Jakob disease was the correct diagnosis in these patients. Seventynine notified cases were classed as definite, 26 as probable and eight as possible. Forty-two were judged not to have had Creutzfeldt-Jakob disease; Alzheimer's disease, with or without myoclonus, proving the most difficult distinction (table 1). Twenty-three further definite cases, not notified as Creutzfeldt-Jakob disease, were obtained from the list already held. Nineteen definite, five probable and two possible cases were found by diligent enquiry at neurological centres. The totals ascertained for the decade are shown in table 2 .

\section{Results}

Although there was naturally some overlap of clinical features, three presentations of CreutzfeldtJakob disease could be distinguished. Of these, by far the most common was the subacute form, rapidly leading to a helpless condition and early death. In the intermediate form the terminal stages were identical but were preceded by a prolonged period of focal or diffuse neurological signs, readily leading to diagnostic confusion. In the amyotrophic form progressive dementia was accompanied or followed by extensive neurogenic muscle atrophy. This form was difficult to classify according to the diagnostic criteria. Such cases with histological confirmation of Creutzfeldt-Jakob disease were regarded as definite and those without were classified as possible. The final classification is shown in table 3. For purposes 
Table 1 Classification of cases certified as dying of Creutzfeldt-Jakob disease but subsequently categorised under other diagnoses

\begin{tabular}{|c|c|c|}
\hline Diagnosis & Patnology & Clinical \\
\hline \multicolumn{3}{|l|}{ Alzheimer's disease } \\
\hline No myoclonus & 1 & 9 \\
\hline Myoclonus & 2 & 8 \\
\hline Motor neuron disease & 1 & 4 \\
\hline \multicolumn{3}{|l|}{ Corticostriatonigral } \\
\hline $\begin{array}{l}\text { degeneration } \\
\text { Non-specific cerebral }\end{array}$ & 3 & \\
\hline $\begin{array}{l}\text { Non-specinc cerebral } \\
\text { atrophy }\end{array}$ & 2 (1 myoclonus) & \\
\hline $\begin{array}{l}\text { Cerebrovascular disease } \\
\text { Parkinson's disease } \\
\text { Alzheimer's and multiple }\end{array}$ & 2 (1 myoclonus) & $\begin{array}{l}2 \text { (1 myoclonus) } \\
1 \text { (myoclonus) }\end{array}$ \\
\hline sclerosis & 1 & \\
\hline Pick's disease & 1 & \\
\hline \multicolumn{3}{|l|}{ Herpes simplex } \\
\hline encephalitis & 1 & \\
\hline \multicolumn{3}{|l|}{ Familial spinocerebellar } \\
\hline \multirow[t]{2}{*}{ Multiple cerebral abscess } & 1 & \\
\hline & 18 & 24 \\
\hline
\end{tabular}

of analysis it was thought appropriate to exclude the four possible subacute cases and the clinical features are therefore described in 158 cases.

\section{Sex distribution}

Of the 158 cases 99 were female and 59 male, a ratio of $1 \cdot 68: 1$.

\section{Age}

Age at death ranged from $30-79$ years, the maximum incidence being in the seventh decade. Eightyone per cent of patients died between the ages of 50 and 69. Age was not significantly different in the three clinical forms of the disease.

\section{Duration of illness}

Duration from the first symptoms to death ranged from three weeks to eight years, the great majority dying within six months. As can be seen in fig 1, duration of illness was an important factor in determining the classification of individual cases, but was not the sole criterion. The mean duration in the subacute group was 5.5 months, in contrast to 33.4 months in the intermediate group and 28.4 months in the amyotrophic cases.

Table 2 Total cases of Creutzfeldt-Jakob disease ascertained from all sources classified by diagnostic type

\begin{tabular}{|c|c|c|}
\hline $\begin{array}{l}\text { Confirmed } \\
\text { Probable } \\
\text { Possible }\end{array}$ & Total & $\begin{array}{r}121 \\
31 \\
10 \\
162\end{array}$ \\
\hline
\end{tabular}

Table 3 Final total of all cases classified by clinical type

\begin{tabular}{lrlr}
\hline Definite and probable cases & Possible cases \\
\hline Subacute & 137 & Subacute & 4 \\
Intermediate & 12 & Amyotrophic & 6 \\
Amyotrophic & 3 & & 10 \\
\hline
\end{tabular}

The subacute form

Prodromal symptoms prior to the development of frank neurological disturbance occurred in 45 $(33 \%)$ of patients with the subacute form of Creutzfeldt-Jakob disease. Commonly, altered personality or malaise are described while some patients developed anorexia and weight loss. Involuntary "twitching" movements of the limbs and sleep disturbance occurred less frequently and depression or emotional lability resulted in psychiatric referral in 13 patients. In contrast to these vague prodromal symptoms, 21 patients ascribed the onset of symptoms to a precipitating event. The association with trivial intercurrent illness may be coincidental but in 10 patients a mild head injury was temporally related to the first symptoms.

The commonest symptom at presentation for medical advice was impairment of higher mental function or behavioural disturbance, with ataxia or dizziness occurring in approximately one third of patients (table 4). In the great majority of patients frank deterioration in mental function became apparent early in the course of the illness but in 12 there was no evidence of dementia on admission to hospital. Characteristically these patients developed symptoms and signs of a progressive cerebellar syndrome with dementia developing late in the course of the illness.

Following the prodromal phase frank neurological symptoms and signs developed. As in previous series the relentless progression of the pathological process was reflected in initial focal cortical disturbance advancing to a diffuse impairment of cerebral function (table 5). Both ataxia and dysphasia were commonly described as an initial symptom and also visual disturbance in the form of blurring or distortion of the image, which was twice as frequent as visual hallucinations. Dementia occurred in all patients and myoclonus, often with a marked startle response, in $82 \%$ of cases. Other involuntary movements of the limbs labelled as "choreoathetoid movements" or simply "twitching" were noted in another $11 \%$ of patients. Akinetic mutism, primitive reflexes and cortical blindness are well recognised in Creutzfeldt-Jakob disease and their relative infrequency in this series probably reflects the difficulties of interpreting hospital notes retros- 


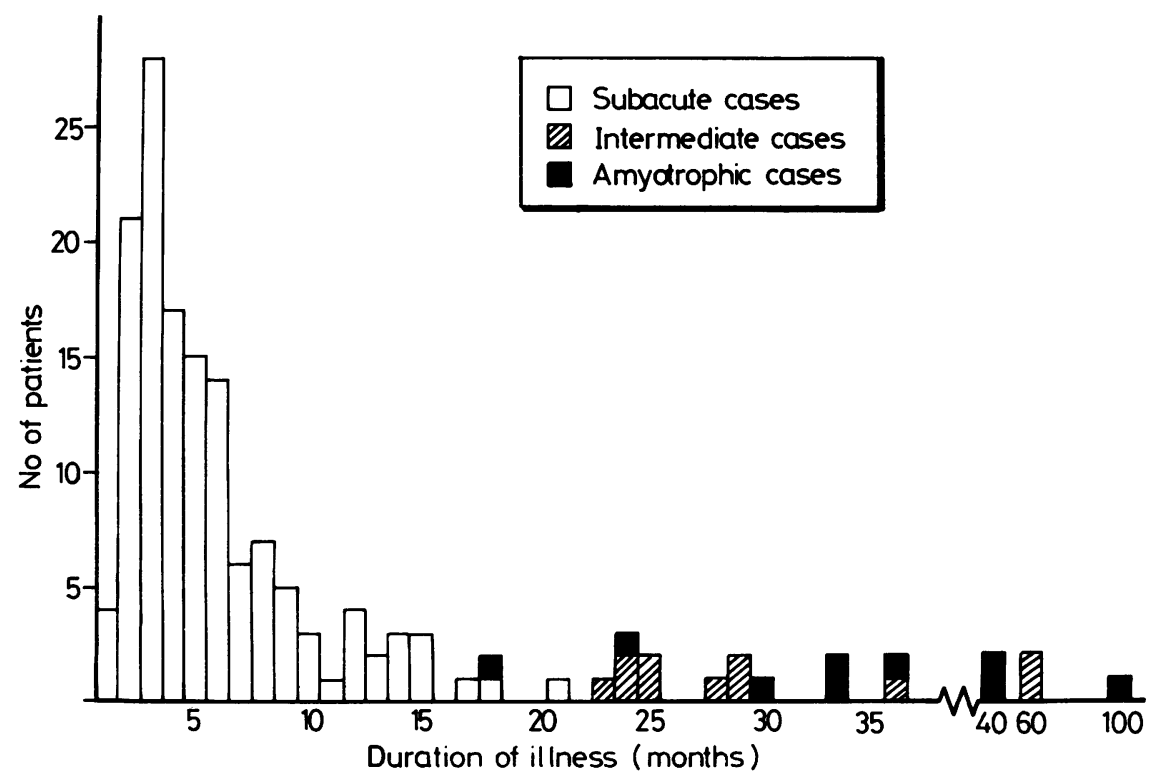

Fig 1 Duration of illness from first symptom to death in 135 subacute cases (in 2 cases duration was uncertain), nine amyotrophic cases and 11 intermediate cases (one case with duration of 16 years is not included in the histogram)

pectively and perhaps a reluctance to elicit or note these signs.

The characteristic course in these patients was of rapid deterioration to a decorticate state that might persist for several months before death.

\section{Intermediate cases}

The intermediate group was heterogeneous with duration of illness ranging from 20 months to 16 years and with varying clinical features. The diagnosis of Creutzfeldt-Jakob disease was, however, confirmed pathologically in each case. The case histories are briefly summarised.

Table 4 Symptoms at presentation of subacute Creutzfeldt-Jakob disease

\begin{tabular}{lr}
\hline & $\%$ \\
Dementia & 21 \\
Ataxia & 19 \\
Behavioural disturbance & 18 \\
Dizziness & 11 \\
Visual disturbance & 9 \\
Involuntary movements & 5 \\
Dysphasia/dysgraphia & 5 \\
Sensory symptoms & 4 \\
Headache & 3 \\
Visual hallucinations & 1 \\
"Blackout attacks" & 1 \\
Others & 2 \\
\hline
\end{tabular}

DC Male, aged 69 yr: 6 months' progressive anxiety, confusion and disorientation terminating in a mute state with rigidity of limbs and myoclonus. The patient was treated with amantadine and improved, becoming mobile and continent. He remained hospitalised for the next four years with little spontaneous speech and died of inhalation of vomit five years after onset of symptoms. ${ }^{6}$

Table 5 Relative frequency of symptoms and signs throughout the course of illness in subacute CreutzfeldtJakob disease

Symptoms

\section{Ataxia} Dysphasia

Visual disturbance Motor disturbance Weight loss/nausea Fear

Visual hallucinations Headache Convulsions

\section{$\%$} 62 50

33
27

27

26

18

17

16
9

Signs

$\begin{array}{lr}\text { Dementia } & 100 \\ \text { Myoclonus } & 82 \\ \text { Pyramidal* } & 79 \\ \text { Dysphasia } & 62 \\ \text { Cerebellar } & 42 \\ \text { Akinetic mutism } & 39 \\ \text { Primitive reflexes } & 30 \\ \text { Cortical blindness } & 13 \\ \text { Extrapyramidal } & 3 \\ \text { Lower motor neuron } & 3\end{array}$

*Rigidity alone classified as pyramidal. 
MF Female, aged 66 yr: 27 month history of bilateral central scotomata for which no cause was found. Admitted with 2 week history of progressive dementia and involuntary movements of the limbs. Became mute and inaccessible and died six weeks after admission.

AI Male, aged $67 \mathrm{yr}$ : Two years' gradually progressive dementia resulting in referral to a psychiatric unit. Rapidly deteriorated after admission with the development of pyramidal signs and akinetic mutism. Died 29 months after the onset of symptoms. Family history of Alzheimer's disease and multiple sclerosis.

RK Male, aged 35 yr: Progressive dementia over 18 months with visual hallucinations and myoclonus in the later stages. Died following a short period of akinetic mutism 25 months after the onset of symptoms.

IL Female, aged 72 yr: 16 years' progressive unsteadiness of gait for which no cause was found. Housebound for 13 years. Admitted with a four-week history of progressive dementia and myoclonus and died six weeks later.

JM Male, aged 63 yr: Two years' tremor, personality change and unsteadiness of gait diagnosed as arteriosclerotic Parkinsonism and treated with partial resolution of symptoms. Admitted with six month history of progressive dementia terminating in a state of akinesia with myoclonus and pyramidal signs. The patient died 25 months after onset of symptoms.

BP Female, aged 49 yr: Two years' progressive unsteadiness of gait followed by a few months' emotional lability and paraesthesiae of limbs. Admitted having become comatose over 24 hours and died ten days later.

GP Male, aged 35 yr: Two years' dysarthria, emotional lability and ataxia of gait. Admitted with short history of progressive dementia and myoclonus and died two months after admission.

IS Male, aged $57 \mathrm{yr}$ : Two years' rigidity of limbs diagnosed and treated as Parkinson's disease. Admitted with short history of progressive dementia and myoclonus resulting in death two months later. Family history of dementia and Parkinson's disease.

LS Female, aged 73 yr: Gradually progressive dementia over at least three years. No myoclonus.

AS Female, aged 61 yr: Five years' slowly progressive dementia. Terminally developed myoclonus and akinetic mutism.

FT Female, aged 69 yr: Two years' progressive dementia with left hemiparesis and probable focal motor seizures. Eventually became mute, rigid and myoclonic, dying four years after the onset of symptoms.

\section{The amyotrophic form}

The course is more stereotyped with slowly progressive dementia over a period of one to seven years prior to the development of wasting and fasciculation of limbs or bulbar musculature. Deterioration is then more rapid, resulting in death within a year. Myoclonus is not a feature in these patients, although athetosis was described in one, and visual failure does not occur. One of this group is of particular interest, having had a sibling who died of pathologically confirmed subacute CreutzfeldtJakob disease and other siblings who died of presenile dementia of uncertain nature. Necropsy showed changes typical of motor neuron disease but the cerebral cortex was surprisingly normal despite severe dementia at the time of death.

\section{Familial associations}

Details of family history were available in 98 cases and in six patients a positive family history of Creutzfeldt-Jakob disease was discovered. Four patients had a sibling who died of definite or probable Creutzfeldt-Jakob disease and the mother of one of these patients also died of the condition. Two further patients had a parent who died of possible Creutzfeldt-Jakob disease. Within these families there were no twin pairs but a discordant twin pair was discovered in the course of the study outside the given decade. The identical twin brother of a patient who died in 1963 of histologically confirmed Creutzfeldt-Jakob disease shows no sign of any neurological disorder 20 years after his brother's death.

Thirteen patients had a first degree relative who died of generative neurological disorder. The spouse of another patient is known to have died of presenile dementia with features which did not suggest Creutzfeldt-Jakob disease.

\section{Treatment}

Amantadine was given to 29 patients, steroids to six patients and cytosine arabinoside to five patients. A number of other drugs were used, including a variety of antibiotics and anticonvulsants. With the exception of the case previously described by Sanders, ${ }^{\circ}$ medication did not alter the course of the illness. In one patient the EEG was thought to have improved but there was no parallel clinical improvement.

\section{Investigations}

Routine haematological and biochemical indices were usually normal and any abnormalities reflected an intercurrent illness such as chest infection. Two patients had persistent hypercalcaemia and abnormal liver function tests were noted in 32 patients out of 80 in whom details were available. Liver function in Creutzfeldt-Jakob disease is to be discussed in detail in a future publication.

Neuroradiological investigations were carried out 
Table 6 Neuroradiological findings in the subacute form of Creutzfeldt-Jakob disease

\begin{tabular}{lll}
\hline & CT scan & Pneumoencephalography \\
\hline Normal & 33 & 13 \\
Mild atrophy & 11 & 13 \\
Definite atrophy & 7 & 7 \\
\hline
\end{tabular}

on the majority of patients. Isotope brain scans or angiography were obtained in 72 patients and were all unhelpful. Air encephalography and latterly CT head scanning showed definite evidence of cerebral or cortical atrophy in only 14 of the 136 cases (table 6 ), usually in advanced cases with mean duration from onset of symptoms to investigation of $5 \frac{1}{2}$ months. One patient had a normal scan on presentation and developed evidence of atrophy three months later when readmitted with severe dementia. Neuroradiological investigations are of use only in the exclusion of other conditions.

The cerebrospinal fluid was examined in 105 patients. A slight pleocytosis was only recorded when a repeat tap was performed in two patients. The CSF protein was within normal limits or minimally elevated in the great majority of patients. Eight estimates, however, exceeded $80 \mathrm{~g} / \mathrm{l}$ with an isolated recording of $200 \mathrm{~g} / \mathrm{l}$ in a confirmed case (fig 2).

The percentage of IgG to total protein was estimated in 15 cases, with estimations greater than $15 \%$ in three.

The electroencephalogram was the most helpful investigation and was characteristic in over $75 \%$ of subacute cases (table 7). The majority of subacute cases with an atypical tracing had only one recording early in the course of the illness and this underlines the importance of obtaining serial recordings in suspected cases. In intermediate cases the EEG is less

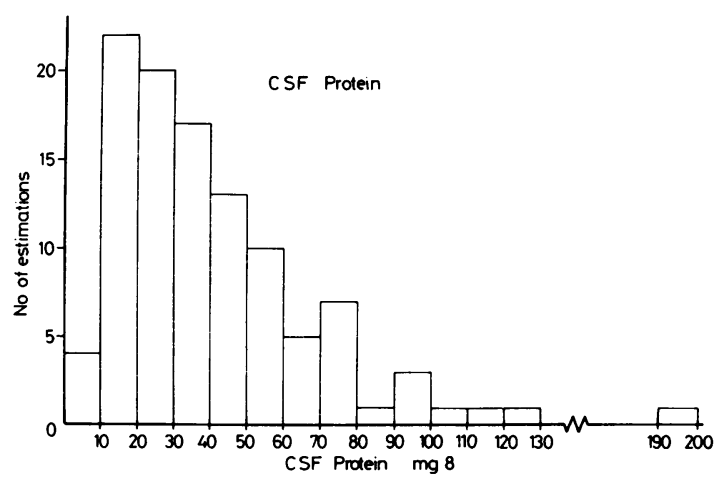

Fig 2 The CSF protein in 96 patients on first tap (nine repeat taps are excluded)
Table 7 EEG findings in Creutzfeldt-Jakob disease classified by clinical type

\begin{tabular}{lrrrr}
\hline & Typical & Atypical & No tracing & Total \\
\hline Subacute & 107 & 20 & 10 & 137 \\
Intermediate & 2 & 7 & 3 & 12 \\
Amyotrophic & 0 & 6 & 3 & 9 \\
\hline
\end{tabular}

often typical and characteristic changes were not seen in the amyotrophic form. The adoption of the EEG as one of the diagnostic criteria therefore presents difficulties in these uncommon forms of the disease.

\section{Discussion}

The typical clinical course in the subacute form of Creutzfeldt-Jakob disease is one of progressive dementia leading after a period of a few weeks to a decorticate state which may persist for many months before death. The clinical features described in this group accorded with previous series ${ }^{7-10}$ and minor differences could be attributed to differing entry criteria and improving diagnostic accuracy.

In contrast, cases of the intermediate type developed a slowly progressive or static focal neurological deficit for months or years prior to the acute illness. This form of Creutzfeldt-Jakob disease was poorly documented in selected series, but in a comprehensive survey of Creutzfeldt-Jakob disease in France ${ }^{8}$ eight similar cases were discovered. Masters $e a l^{11}$ have related extended duration of illness to the presence of senile or kuru plaques but such changes were not present in any of the 12 cases of intermediate duration. In four subacute cases plaques were discovered but not associated with extended duration of illness. However the gradually progressive course in the intermediate cases, often with initial dementia, makes the clinical distinction from Alzheimer's disease problematic and this is illustrated by the 20 cases certified as CreutzfeldtJakob disease which were subsequently reclassified as Alzheimer's disease. Particular difficulty arises in Alzheimer's disease with myoclonus and this is accentuated in cases with relatively short duration. Furthermore the "typical" EEG changes of Creutzfeldt-Jakob disease have been described in Alzheimer's disease ${ }^{12}$ making the clinical distinction from the unusual intermediate form of CreutzfeldtJakob disease almost impossible.

The amyotrophic form of Creutzfeldt-Jakob disease is more generally recognised with a frequency of $5-15 \%$ of cases. In contrast to the subacute form, myoclonus, cortical blindness and the characteristic EEG do not occur and, despite the presence of 
spongiform change in the cerebral cortex, transmission experiments have been unsuccessful. ${ }^{13}$ This raises the possibility that the amyotrophic form is not a "slow virus" disease and that the pathological changes are coincidental.

The specificity of spongiform change, as opposed to status spongiosus, as a characteristic of Creutzfeldt-Jakob disease has been stressed by Masters, ${ }^{14}$ but this view has been recently challenged, ${ }^{15}$ accentuating the importance of transmission to confirm the presence of the agent. The long duration of illness in amyotrophic patients may reflect a virus strain of low virulence or a low infectious dose, resulting in extended incubation and apparently failed transmission, as with species to species transmission in the laboratory. ${ }^{16}$ There is, however, no firm evidence that amyotrophic Creutzfeldt-Jakob disease is a slow virus disease although it is of interest that the subacute form and amyotrophic form should occur in siblings of a family with apparently inherited Creutzfeldt-Jakob disease.

The overall familial incidence of $6 \%$ in this series contrasts with the estimated familial incidence of $15 \%$ in a review of the worldwide epidemiology of Creutzfeldt-Jakob disease. ${ }^{5}$ In individual series higher figures are quoted with, for example, a familial incidence of $47 \%$ in Chile ${ }^{17}$ and $35 \%$ in Libyan born Israelis. ${ }^{18}$ In a comprehensive survey of Creutzfeldt-Jakob disease in France, ${ }^{19}$ however, a 9\% familial incidence was discovered, a figure comparable with this series. The low familial incidence may reflect either the difficulties of retrospectively obtaining an accurate family history or an artificially high familial incidence in relatively selected series due to extensive investigation of individual families.

A further point of contrast from previous reports is the preponderance of female patients. In past series the sex incidence has been equal and the female bias in this series is unexplained. However, this finding has been continued in the prospective survey of Creutzfeldt-Jakob disease at present being carried out in England and Wales.

The routine investigation of patients with Creutzfeldt-Jakob disease has been unrewarding. The only biochemical abnormality observed in this series was minor elevation of liver enzymes or bilirubin in a minority of patients. The CT scan was usually normal in subacute cases and cortical or cerebral atrophy occurred only late in the course of the illness when the diagnosis was usually clear. Neuroradiological investigations in the subacute illness were thus helpful only in the exclusion of other conditions. In the intermediate and amyotrophic forms the CT scan was more likely to show atrophy but this was nonspecific. As the EEG is also unhelpful in the majority of these patients, the diagnosis of
Creutzfeldt-Jakob disease rests on the pathological findings. The CSF was normal in the great majority of patients but a minor elevation of CSF protein may occur and in one confirmed case a level of $2 \mathrm{~g} / 1$ was recorded. Galvez et $a l^{20}$ have described a significantly higher mean total CSF protein content in cases of Creutzfeldt-Jakob disease in relation to a control group. The concentration of IgG was also found to be increased as with three patients in this series.

The accurate diagnosis of subacute cases of Creutzfeldt-Jakob disease presents little difficulty but both intermediate and amyotrophic cases share clinical features with other more common conditions and may be impossible to diagnose in life. Pathological confirmation of the diagnosis is vital for an increased understanding of the epidemiology of Creutzfeldt-Jakob disease and the, at present enigmatic, mechanism of transmission of the agent.

We are grateful for the co-operation of many clinicians, pathologists, clinical neurophysiologists and hospital medical records officers. In particular we thank Dr JT Hughes for unfailing help. The project was supported by the Medical Research Council.

\section{References}

${ }^{1}$ Gibbs CJ, Gajdusek DC, Asher PM, et al. CreutzfeldtJakob disease (spongiform encephalopathy): transmission to the chimpanzee. Science 1968;161:388-9.

${ }^{2}$ Manuelidis EE. Transmission of Creutzfeldt-Jakob disease from man to the guinea pig. Science 1975; 190:571-2.

${ }^{3}$ Will RG, Matthews WB. Evidence for case-to-case transmission of Creutzfeldt-Jakob disease. $J$ Neurol Neurosurg Psychiatry 1982;45:235-8.

${ }^{4}$ Matthews WB. Epidemiology of Creutzfeldt-Jakob disease in England and Wales. J Neurol Neurosurg Psychiatry 1975;45:210-3.

${ }^{5}$ Masters CL, Harris JO, Gajdusek DC, Gibbs CJ, Bernouilli C, Asher DM. Creutzfeldt-Jakob disease: patterns of world-wide occurrence and the significance of familial and sporadic clustering. Ann Neurol 1979;5:177-88.

' Sanders WL. Creutzfeldt-Jakob disease treated with amantadine. J Neurol Neurosurg Psychiatry 1979; 42:960-1.

${ }^{7}$ Matthews WB. The clinical aspects of slow virus infections of the human brain. In: Illis LS, ed. Viral Diseases of the Central Nervous System. London: Bailliere Tindall, 1975:145-60.

${ }^{8}$ Brown P, Cathala F, Sadowsky D, Gajdusek DC. Creutzfeldt-Jakob disease in France: II Clinical characteristics of 124 verified cases during the decade 1968-1977. Ann Neurol 1979;6:430-7.

${ }^{9}$ Traub R, Gajdusek DC, Gibbs CJ. Transmissible virus dementia; the relation of transmissible spongiform encephalopathy to Creutzfeldt-Jakob disease. In: 
Kinsbane M, Smith L, eds. Aging and Dementia. New York: Spectrum, 1977:91-172.

${ }^{10}$ Bernouilli, CC, Masters CL, Gajdusek DC, Gibbs CJ, Harris JO. Early clinical features of Creutzfeldt-Jakob disease (subacute spongiform encephalopathy). In: Prusiner SB, Hadlow WJ, eds. Slow Transmissible Diseases of the Nervous System, vol. 1. New York, Academic Press, 1978:229-51.

${ }^{11}$ Masters CL, Gajdusek DC, Gibbs CJ. Creutzfeldt-Jakob disease virus isolations from the Gerstmann-Sträussler syndrome with an analysis of the various forms of amyloid plaque deposition in the virus-induced spongiform encephalopathies. Brain 1981; 104:559-88.

${ }^{12}$ Watson CP. Clinical similarity of Alzheimer and Creutzfeldt-Jakob disease. Ann Neurol 1979;6:3689.

${ }^{13}$ Salazar C, Masters C, Gajdusek DC, Gibbs CJ. Syndromes of amyotrophic lateral sclerosis and dementia: relation to transmissible Creutzfeldt-Jakob disease. Ann Neurol 1983;14:17-26.

${ }^{14}$ Masters CL, Richardson EP Jr. Subacute spongiform encephalopathy (Creutzfeldt-Jakob disease): the nature and progression of spongiform change. Brain 1978;101:333-44.
${ }^{15}$ Beck E, Daniel PM, Davey AJ, Gajdusek DC, Gibbs CJ. The pathogenesis of transmissible spongiform encephalopathy: an ultrastructural study. Brain 1982;105:755-86.

${ }^{16}$ Manuelidis EE, Manuelidis L. Observations on Creutzfeldt-Jakob disease propagated in small rodents. In: Prusiner SB, Hadlow WJ, eds. Slow Transmissible Diseases of the Nervous System, vol. 2. New York, Academic Press, 1979:147-73.

${ }^{17}$ Galvez S, Masters CL, Gajdusek DC. Descriptive epidemiology of Creutzfeldt-Jakob disease in Chile. Arch Neurol 1980;37:11-14.

${ }^{18}$ Neugut RH, Neugut AI, Kahawa E, Stein Z, Alter M. Creutzfeldt-Jakob disease: familial clustering among Libyan born Israelis. Neurology (Minneap) 1979;29:225-31.

${ }^{19}$ Brown P, Cathala F, Gajdusek DC. Creutzfeldt-Jakob disease in France: III Epidemiological study of 170 patients dying during the decade 1968-1977. Ann Neurol 1979;5:438-46.

${ }^{20}$ Galvez S, Farcas A, Monari M. Cerebrospinal fluid and serum immunoglobulins and $\mathrm{C}_{3}$ in Creutzfeldt-Jakob disease. Neurology (Minneap) 1979;29:1610-12. 